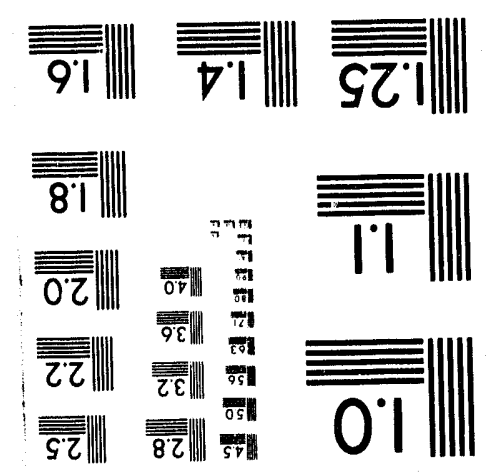



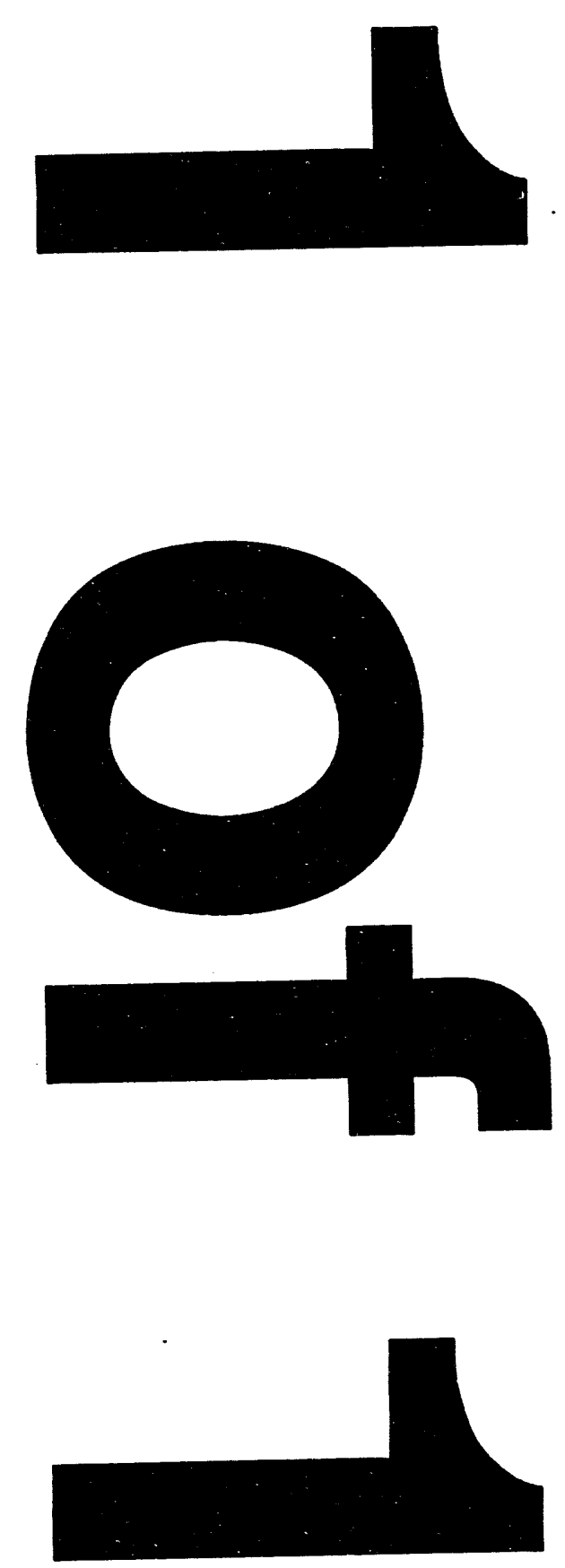


\section{A NUMERICAL COMPARISON OF SENSITIVITY ANALYSIS TECHNIQUES (U)}

by

D. M. Hamby

Westinghouse Savannah River Company

Savannah River Site

Aiken, South Carolina 29808

A document prepared for.

Technometrics

DOE Contract No. DE-AC09-89SF18035

This paper was prepared in connection with work done under the above contract number with the U.S.

Department of Energy. By acceptance of this paper, the publisher and/or recipient acknowledges the U.S. Government's right to retain a nonexclusive, royalty-free license in and to any copyright covering this paper, along with the right to reproduce and to authorize others to reproduce all or part of the copyrighted paper. 
WSRC-MS-93-586

A NUMERICAL COMPARISON OF SENSITIVITY ANALYSIS TECHNIQUES

D. M. Hamby

Westinghouse Savannah River Company

Savannah River Technology Center

Aiken, SC 29808 


\section{DISCLAIMER}

This report was prepared as an account of work sponsored by an agency of the United States Government. Neither the United States Government nor any agency thereof, nor any of their employees, makes any warranty, express or implied, or assumes any legal liability or responsibility for the accuracy, completeness, or usefulness of any information, apparatus, product, or process disclosed, or represents that its use would not infringe privately owned rights. Reference herein to any specific commercial product, process, or service by trade name, trademark, manufacturer, or otherwise does not necessarily constitute or imply its endorsement, recommendation, or favoring by the United States Government or any agency thereof. The views and opinions of authors expressed herein do not necessarily state or reflect those of the United States Government or any agency inereof.

This report has been reproduced directly from the best available copy.

Available to DOE and DOE contractors from the Office of Scientific and Technical Information, P. O. Box 62, Oak Ridge, TN 37831; prices available from (615) 576-8401.

Available to the public from the National Technical Information Service, U. S. Deparment of Commerce, 5285 Port Royal Rd., Springfield, VA 22161 
ABSTRACT 


\section{INTRODUCTION}

Engineering and scientific phenomena are often studied with the aid of mathematical models designed to simulate complex physical processes. In the nuclear industry, modeling the movement and consequence of radioactive pollutants is extremely important for environmental protection and facility control. One of the steps in model development is the determination of the parameters most influential on model results. A "sensitivity analysis" of these parameters is not only critical to model validation but also serves to guide future research.

A previous manuscript (Hamby 1994) detailed many of the available methods for conducting sensitivity analyses. The current paper is a comparative assessment of several methods for estimating relative parameter sensitivity. Method practicality is based on calculational ease and usefulness of the results. It is the intent of this report to demonstrate calculational rigor and to compare parameter sensitivity rankings resulting from various sensitivity analysis techniques. An atmospheric tritium dosimetry model (Hamby 1993) is used here as an example, but the techniques described can be applied to many different modeling problems. Other investigators (Rose 1983; Dalrymple and Broyd 1987) present comparisons of sensitivity analyses methodologies, but none as comprehensive as the current work.

\section{SENSITIVITY ANALYSIS METHODS}

The sensitivity of a tritium dose model (Hamby 1993) to 21 input parameters has been analyzed using fourteen methods of sensitivity analysis. A comprehensive review of these methods is given by Hamby (1994). The sensitivity methods include the utilization 
of the following one-at-a-time sensitivity measures: partial derivatives (PD), one standard deviation increase and decrease of inputs $( \pm S D)$, a $20 \%$ increase and decrease of inputs $( \pm 20 \%)$, and a sensitivity index (SI). The sensitivity measures investigated that utilize an array of input and output values generated through random sampling include: an importance index (II), a relative deviation of the output distribution (RD), a relative deviation ratio (RDR), partial rank correlation coefficients (PRCC), standardized regression coefficients (SRC), and rank regression coefficients (RRC). Four additional techniques have been used to estimate parameter sensitivity rankings based on the partitioning of input data based on the distribution of associated model results (Crick et al. 1987). These methods include the Smirnov test (S), the Cramer-von Mises test (CM), the Mann-Whitney test (MW), and the squared-ranks test (SR).

A simplistic and qualitative approach to determining parameter sensitivity is achieved by aggregating the mathematical model, i.e., algebraically combining exposure pathway models, evaluating the resulting equation using best-estimate parameter values, and assessing the relative contribution to dose via each pathway component. It is a simple task to aggregate the tritium model utilized for this paper (Hamby 1993). Total atmospheric tritium dose to a receptor is the sum of the inhalation and ingestion pathway doses and is given by,

$$
\begin{gathered}
D=\left\{\frac{4.84 \times 10^{-9} T_{e} f_{w} C^{a} R_{p a}}{M H}\right\} \cdot\left\{\left(2.74 U_{m} f_{m} f_{p m} I_{m} e^{-\left(\lambda l_{m}\right)}\right)+\left(2.74 U_{b} f_{b} f_{p b} I_{b} e^{-\left(\lambda t_{b}\right)}\right)\right. \\
\left.+\left(1000 U_{v} f_{v}\right)+\left(1000 U_{l} f_{l}\right)+\left(\frac{(1.5) B R H}{f_{w} R_{p a}}\right)\right\}
\end{gathered}
$$

where the constants account for unit conversions. Distribution definitions and characteristics of parameters are given in Tables 1 and 2 . The five components in the right set of brackets represent the five exposure pathways: 1) milk consumption, 2) beef consumption, 3) produce consumption, 4) leafy vegetable consumption, and 5) inhalation, 
respectively. It is immediately apparent that the model will be sensitive to some degree to three of the parameters in the left set of brackets $\left(T_{e}, C^{a}\right.$, and $\left.M\right)$ since their values influence all pathway dose estimates. The three remaining parameters in the left brackets $\left(f_{w}, R_{p a}\right.$, and $\left.H\right)$ cancel in the inhalation portion of the equation, therefore, they are expected to be sensitive, but to have less influence than $T_{e}, C^{a}$, and $M$, since all pathway dose estimates are not affected by their values.

Differential Sensitivity Analysis (PD). Differential analyses, also referred to as the direct method, are structured on the behavior of the model for a base-case scenario, e.g., all parameters set equal to their mean value. Differential sensitivity analysis is based on partial differentiation of the aggregated model. When an explicit algebraic equation describes the modeled relationship, the sensitivity coefficient for a particular independent variable is calculated from the partial derivative of the dependent variable with respect to the independent variable. Partial derivatives of the aggregated equation describing the atmospheric tritium model were calculated for each input parameter. Table 3 shows the numerical results of these calculations. The partial is multiplied by the ratio of the parameter value and the model result for the base-case scenario to remove the effects of units.

One-at-a-Time Sensitivity Measures $( \pm 20 \%, \pm S D)$. This type of sensitivity analysis only addresses parameter sensitivity relative to the point estimates chosen for the parameters held constant. One test was conducted where the sensitivity measure was determined by adjusting parameter values by a percentage of their base-case value. The sensitivity measure $( \pm 20 \%)$ was determined by calculating the ratio of model results while the input parameter was varied by $\pm 20 \%$. 
A more powerful test of local sensitivity examines the change in output as each parameter is individually increased by a factor of its standard deviation $( \pm S D)$. This type of sensitivity measure takes into account the parameter's variability and the associated influence on model output. This test is similar to that described above except that parameters were varied by one standard deviation of their input distribution rather than $20 \%$ of their base-case value.

Factorial design (Box et al. 1978) is another one-at-a-time analyses, however, this method requires a great deal of effort when dealing with large models. A simple factorial design for the twenty-one parameters used here and only two levels requires more than twomillion model runs. In some cases, a fractional factorial method can be implemented to reduce the number of trials to a manageable size.

The Sensitivty Index (SI). Another of the simple methods of determining parameter sensitivity is to calculate the output percent difference when varying one input parameter from its minimum value to its maximum value. The "sensitivity index" was introduced by Hoffman and Gardner (1983) to account for all possible values when determining parameter sensitivity.

\section{Parameter Sensitivity Using Random Sampling Techniques}

To this point, sensitivity has been assessed on parameters one-at-a-time without regard to the combined variability resulting from considering all input parameters simultaneously. Random sampling (e.g., simple random sampling, Monte Carlo, Latin hypercube, etc.) of input parameters generates input and output distributions useful in assessing model and parameter uncertainties in a "global" sense, i.e., sampling over the entire range of possible parameter values. 
The Importance Index (II). Hoffman and Gardner (1983) introduce an "importance index" which is equal to the variance of the parameter value divided by the variance of the dependent values. For additive models the variance is of the raw data, whereas for simple multiplicative models the variance is of the log-transformed data. The model under consideration here is definitely not a simple additive or multiplicative model. Importance indices were calculated, however, using the input and output data following a $\log$ transformation, as would be carried out for a multiplicative model.

The "Relative Deviation" Method (RD). This sensitivity ranking method measures the amount of variability in the model output while varying each input parameter according to its probability density function. This method is similar to local sensitivity methods with the exception that a larger sampling is made of the input distribution. The sensitivity figure-of-merit is the "relative deviation" (RD), the ratio of the standard deviation to the mean of the output's density function.

The "Relative Deviation Ratio" (RDR). This test statistic is the ratio of the output distribution's relative deviation to the input distribution's relative deviation. In principle, this sensitivity measure is very similar to the importance index calculated above. A large value of the RDR indicates that either the output distribution varies widely or that the input distribution is relatively narrow.

The Partial Rank Correlation Coefficient (PRCC). Correlation can be determined qualitatively by scatter plots of input vs output values (Fig. 1), or quantitatively by calculation of a correlation coefficient, $r$. The larger the absolute value of $r$, the stronger the degree of linear relationship between the input and output values (IAEA 1989). One of the problems encountered in calculating test statistics from raw data is that the data are 
not neces sarily linear. For this reason, parameter sensitivity was not calculated based on simple correlation.

A method of reducing the effects of nonlinear data is to use the rank transformation. If the input/output associations are monotonic then rank transformations of the input and output values (i.e., replacing the values with their ranks) will result in linear relationships and the rank correlation coefficient (RCC) will indicate the degree of monotonicity between the input and output sample values (IAEA 1989). The RCC can be calculated using the equation for simple correlations with the exception of operating on the rank transformed data (Iman and Conover 1979).

RCCs have been calculated for the correlations between each input parameter and the output. Strong correlations between input parameters, however, may influence these input/output correlations. Partial correlation coefficients (PCC) are calculated to account for correlations among other input variables. Again, partial correlations are not necessarily linear, therefore sensitivity rankings were not calculated using PCCs.

The rank transformation also can be applied to partial correlation as a test of monotonicity between input and output variables while accounting for relationships between input parameters. The partial rank correlation coefficient (PRCC) is widely utilized for sensitivity studies. Because of the difficulty in determining correlations between input parameters, many investigators assume that input correlations do not exist in model evalıations. Therefore, the use of RCCs or PRCCs will result in identical sensitivity rankings, although actual values of the correlation coefficients will differ (Table 4). 


\section{Standardized Regression Coefficients and Rank Regression Coefficients (SRC \& RRC).}

The use of the regression technique allows the sensitivity ranking to be determined based on the relative magnitude of the regression coefficients. The coefficients are indicative of the amount of influence the parameter has on the whole model. Because of units and the relative magnitudes parameters, a standardization process is sometimes warranted. Standardization in regression analysis takes place in the form of a transformation by ranks or by the ratio of the parameter's standard deviation to its mean. The rank regression coefficient (RRC) is calculated by performing regression analysis on the rank transformed data rather than the raw data. The RRC generally is referred to as a standardized RRC. This terminology, however, is misleading and redundant since the data are standardized by the rank transformation process.

\section{Sensitivity Tests Involving Segmented Input Distributions}

These statistical tests involve some form of dividing or segmenting input parameters into two or more empirical distributions based on an associated partitioning of the output distribution (Crick et al. 1987). In one of the two examples presented here, the median value of the dose distribution is chosen as the partitioning point. For a given parameter, all input data associated with a dose below the median are said to belong to one random sample while input data associated with a dose above the median belong to a second random sample. These two random samples are used to generate the empirical distributions. Means, medians, variances, and other characteristics of these empirical distributions are compared to determine whether the distributions are statistically identical. In the second numerical example, input data are partitioned according to the 90th percentile dose. Since their results are specific to the partitioning point, the sensitivity tests performed on the segmented data are not compared to the previous tests. 
The Smirnov Test (S). The Smirnov test operates on the two empirical distributions, $S_{1}(x)$ and $S_{2}(x)$, generated as a result of partitioning a given input parameter distribution. The degree of similarity, measured as the greatest absolute difference in the vertical direction between distributions, is used to indicate the sensitivity between the input and output values. The resulting sensitivity ranking is based on the distribution partitioning; ranks resulting from data partitioned based on the output median value may be different than ranks resulting from data partitioned based on the 90 th percentile.

The Cramer-von Mises Test $(C M)$. The Cramer-von Mises test is very similar to the Smirnov test in that its purpose is to determine whether two empirical distributions are statistically identical. The test statistic is the sum of all squared vertical distances between the two empirical distributions.

The Mann-Whitney Test (MW). The Mann-Whitney test, also known as the Wilcoxon test, is utilized to compare the means of two independent samples (Conover 1980). Two distribution functions are ordered as a single sample and ranks are assigned based on the ordering. The test statistic is the sum of the resulting ranks of data from one of the distributions. Since the Mann-Whitney test is two-tailed (the mean of $\mathrm{X}$ could be larger or smaller than the mean of $Y$ ), sensitivity ranks are based on a normalized value of $T$ (Hamby 1994). After normalization, the smaller values of $\mathrm{T}$ indicate the more sensitive parameters since the means of the distributions show a greater difference based on the partitioning of input data.

The Squared-Ranks Test (SR). The variances of two independent samples can be compared using the squared-ranks test. Ranks are not based on the raw data, rather on the absolute difference between the random sample and the sample mean. For parameter 
ranking purposes, the normalization procedure executed on the Mann-Whitney statistic also is necessary with the squared-ranks statistic.

\section{RESULTS}

The sensitivity results for each test are given in Tables 5 and 6 . Tables 7 and 8 present the sensitivity measures in terms of ranks. Since one sensitivity method does not stand out as being universally accepted as the "correct" method, a "true" sensitivity ranking has been determined. For the sake of comparing methods, the "true" sensitivity ranking is based on the sum of ranks over the methods shown in Table 7. The parameter with the lowest total rank is considered to have the greatest sensitivity.

The relative performance of each method was determined by comparing the methodspecific sensitivity ranking to the "true" ranking. A "performance index" was calculated for this comparison. The performance index is a test of trend and is the sum of the squared-differences of the compared ranks, the T statistic in Spearman's $\rho$ (Conover 1980). Table 9 shows an example of the calculation of the performance index. A smaller index indicates a better trending of the method-specific and true rank orders. The "true" sensitivity ranking and the method performance ranking are shown in Table 10.

Parameters are listed in decreasing order of sensitivity and the sensitivity techniques are listed in order of increasing performance index. Sensitivity ranks of the top ten parameters for each method are given in the table.

Table 11 shows the ten most sensitive parameters based on the data-partitioned sensitivity methods. Because of the nature of these sensitivity tests, their results are not compared quantitatively to the "true" sensitivity ranking. For convenience and a qualitative view of 
their performance, however, the table lists the model parameters in the same order as the "true" ranking.

The test of trend using Spearman's $\rho$ also was used to calculate a performance index and compase sensitivity ranks between methods. These comparisons show which tests behave similarly and which tests appear to be inappropriate for sensitivity analysis, at least for the type of model considered in this work. The sums of squared-differences are given in Tables 12 and 13. Again, smaller values indicate better trending of ranks and greater parity between methods. As an example, the performance index for the comparison between the $\pm 20 \%$ and PD methods is 1.5 , indicating remarkable agreement between the two rank orders. The techniques involving partitioning of input distributions have not been compared with the other methods.

\section{DISCUSSION}

A number of sensitivity analysis techniques have been presented (Hamby 1994). These techniques were utilized to determine relative sensitivity of parameters used in an atmospheric tritium dosimetry model (Hamby 1993). A "true" sensitivity ranking was determined by considering the resultant ranking order of all sensitivity tests. This "true" ranking is the basis for comparison of sensitivity methods and for determining method performance.

As stated earlier, the performance of each method is measured by how closely the method-specific sensitivity rank compares to the "true" rank. The performance index (PI) indicates that the SI and RD methods produce ranking results that are most similar to the "true" rank (refer to Table 10). It is encouraging to see that all methods (except the importance index) produce le same general ranking of parameter sensitivity. The II 
method is meant to be used with simple additive or multiplicative models; it is apparently not appropriate as a sensitivity measure for the model used in this example. The SI method chooses all of the top ten sensitive parameters while the RD method chooses the top six parameters in the "true" order. The first five methods choose the top six parameters, but not necessarily in the "true" order.

The top ten parameter sensitivity rankings determined by the partitioned data methods are given in Table 11. The ranks based on the Smirnov, Cramer-von Mises, and MannWhitney tests appear to be very similar to the "true" rank. The three methods produce the three most sensitive parameters regardless of the partitioning point. Ranking results from the squared-ranks test are much different and show greater sensitivity to the selection of partitioning point than the others.

Table 12 provides a comparison between sensitivity methods; the PI is calculated for each combination of ten sensitivity techniques discussed. Small values of PI indicate similar sensitivity rankings. The partial derivative method is the most fundamental of the "local" sensitivity analysis techniques. It is appropriate only for relatively small changes (on the order of several percent) in the input parameter. It is not surprising, therefore, that sensitivity ranks based on the PD and $\pm 20 \%$ methods result in very similar orders. The standard deviation increments $( \pm S D)$ can at times be quite large, therefore, the $\pm S D$ ranks are not as similar. The RDR method acts "globally", yet produces rankings similar to PD and $\pm 20 \%$. As suggested by Table 10 and confirmed in Table 12, rankings obtained from the sensitivity index (SI) and the relative deviation (RD) are quite similar. And, to a lesser degree, the SI and RD methods produce results similar to the \pm SD method. Parameter sensitivity ranks based on the rank regression coefficient (RRC) are similar to the rankings from the SI, $\pm \mathrm{SD}$, and PRCC techniques. The importance index (II), meant 
for simple multiplicative models, produces results unlike any of the other methods; its utility is questionable.

The Smirnov (S), Cramer-von Mises (CM), Mann-Whitney (MW) tests all produce very similar parameter sensitivity rankings when partitioned based on the median and 90th percentile model resuits (Table 13). It is not surprising that the rankings based on the Smirnov and Cramer-von Mises tests are similar since the two show little difference in their statistical power (Conover 1980). Parameters can be ranked entirely different for tests operating on a partitioning point at the median and at the 90 th percentile. For example, the performance indices show that the rankings between the CM test at the median and 90th percentiles are markedly different than the similaries between the CM test and the MW test, at both partitioning points. Ranking results from the squared-ranks (SR) tests are quite different than the other tests operating on partitioned data sets. The variances of the two empirical distributions generated by the partitioning process apparently are not good indicators of parameter sensitivity.

\section{CONCLUSIONS}

A number of sensitivity analysis techniques have been presented. The majority of the techniques result in similar rankings of the top several sensitive parameters. Since the actual ranking is not as important as the general ranking, most of the techniques would be appropriate for sensitivity analysis of the type of model considered in this report. The criteria most important, therefore, is the ease with which the sensitivity method can be performed. With the proper software, all methods presented here are relatively easy to perform. Given a moderate number of parameters and a hand calculator, however, the sensitivity index is the easiest and most reliable sensitivity measure. The SI can be 
calculated without knowledge of the parameter distribution and without the use of random sampling schemes or large computer programs.

The relative deviation $(\mathrm{RD})$ is a reliable measure of parameter sensitivity. Calculation of the $\mathrm{RD}$ is quite simple if a sampling technique is employed and the output values are stored for the statistical analysis. This analysis requires a one-at-a-time approach, however, and can be labor intensive. Estimating sensitivity based on the relative deviation ratio (RDR) is not recommended since its results are less reliable and it requires more calculational rigor than the RD.

Rank regression coefficients are easily obtained with the use of commerically available software. An electronic spreadsheet and the SAS statistical package (SAS Institute Inc., Cary, North Carolina) were utilized for this analysis. The calculation of sensitivity rankings by varying the parameter by its standard deviation ( $\pm S D)$ is as simple as calculating the sensitivity index with the exception that some knowledge of the parameter distribution must be available. Varying the input parameter by a standard amount $( \pm 20 \%)$ is an easy test to perform, but its reliability is less desirable than the simpler SI method.

The simplest approach to sensitivity analysis is the one-at-a-time method where sensitivity measures are determined by varying each parameter independently while all others are held constant. These sensitivity techniques, however, become rather time intensive with large numbers of parameters. The most fundamental of sensitivity techniques is the direct method of using partial differentials to calculate the rate of change in the model output with respect to a given input parameter. The one-at-a-time techniques are valid only for small variability in parameter values and the partials must be recalculated for each change in the base-case scenario. 
Crick et al. (1987) propose statistically analyzing selected input vectors by segmenting input values based on their relationship to some critical output value (e.g., the mean, median, or 90 th percentile of the output distribution). This type of analysis provides detailed information on parameter sensitivity based on the calculated output. The nonparametric tests on partitioned data sets are very labor intensive yet are not necessarily beneficial unless a particular question is to be answered regarding the sensitivity of a parameter with respect to model output. 


\section{REFERENCES}

Box, G.E.P.; Hunter, W.G.; Hunter, J.S. 1978. Statistics for experimenters: an introduction to design, data analysis, and model building. John Wiley \& Sons. New York.

Conover, W.J. 1980. Practical nonparametric statistics. 2nd Edition. John Wiley \& Sons. New York.

Crick, M.J.; Hill, M.D.; Charles, D. 1987. The role of sensitivity analysis in assessing uncertainty. In: Proceedings of an NEA workshop on uncertainty analysis for performance assessments of radioactive waste disposal systems. Paris: OECD; 1-258.

Dalrymple, G.J.; Broyd, T.W. 1987. The development and use of parametric sampling techniques for probabilistic risk assessment. IAEA-SR-111/54P. In: Implications of Probabilistic Risk Assessment (Cullingford, Shah, and Gittus eds.) Elsevier. London.

Hamby, D.M. 1993. A probabilistic estimation of atmospheric tritium dose. Health Physics. 65:33-40.

Hamby, D.M. 1994. A review of techniques for parameter sensitivity analysis. Submitted to Technometrics.

Hoffman, F.O.; Gardner, R.H. 1983. Evaluation of uncertainties in environmental radiological assessment models. In: Till, J.E.; Meyer, H.R. eds. Radiological assessments: a textbook on environmental dose assessment. Washington, DC: U.S. Nuclear Regulatory Commission; Report No. NUREG/CR-3332. 
Iman, R.L.; Conover, W.J. 1979. The use of the rank transform in regression. Technometrics. 21:499-509.

Iman, R.L.; Conover, W.J. 1980. Smail sample sensitivity analysis techniques for computer models, with an application to risk assessment. Communications in Statistics Theory and Methods. A9:1749-1842.

International Atomic Energy Agency. 1989. Evaluating the reliability of predictions made using environmental transfer models. Vienna: Safety Series No. 100. Report No. STI/PUB/835; $1-106$.

Rose, K.A. 1983. A simulation comparison and evaluation of parameter sensitivity methods applicable to large models. In: Analysis of Ecological Systems: State-of-the-Art in Ecological Modelling (Lauenroth, Skogerboe, and Flug eds.) Elsevier. New York. 


\section{CAPTIONS}

Fig. 1 Sample scatter plot showing the relationship between one input parameter and the model output. Plot is of individual dose from tritium exposure (all pathways) versus tritium oxide concentration in air (Hamby 1993). 


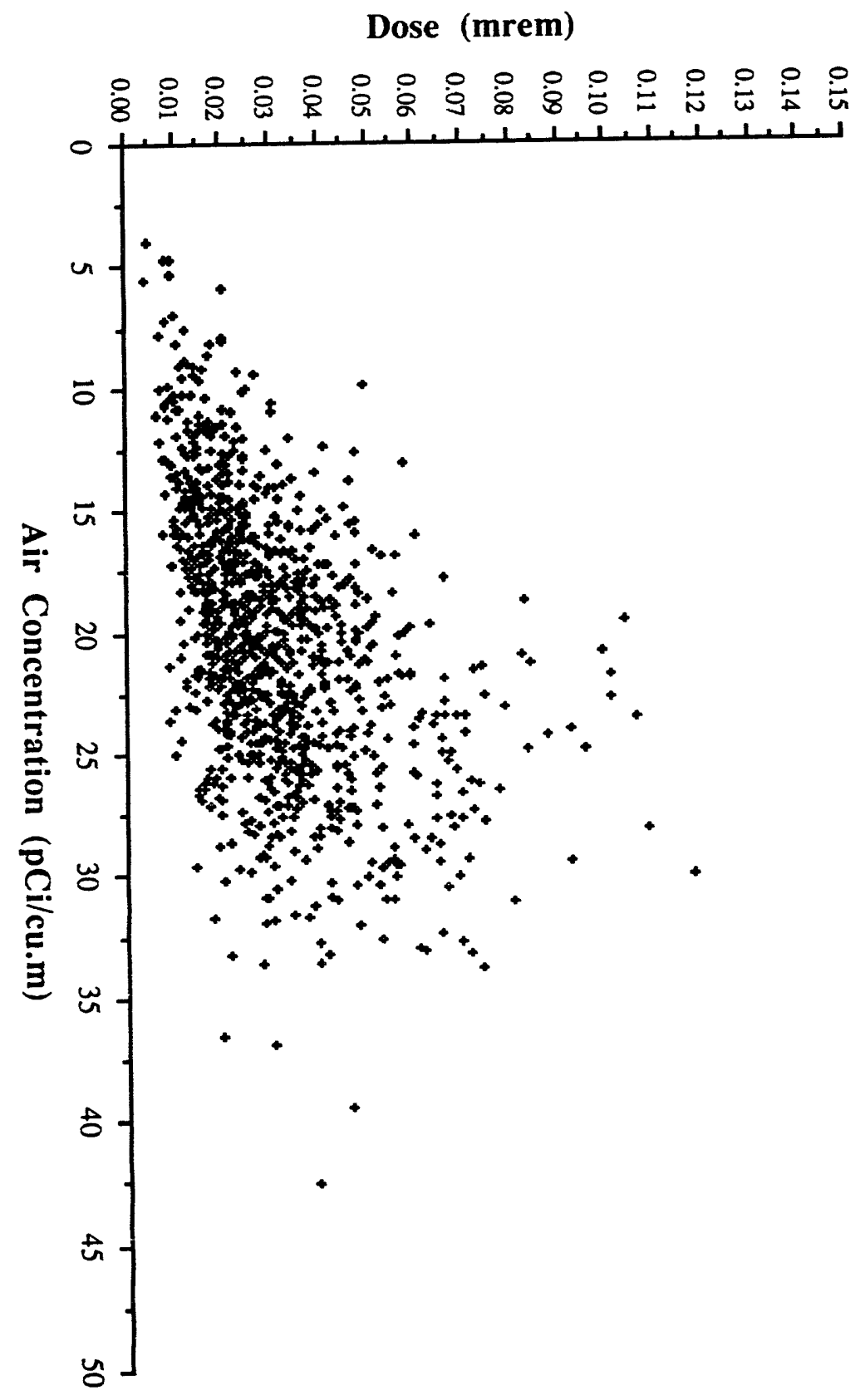


Table 1. Parameter definitions and applicable exposure pathway models.

Description
Parameter
Exposure

Pathway*
Average annual concentration of tritium

Effective biological half-life of tritium

Mass of soft tissue in adult male

Average annual absolute humidity

Percent water in vegetation

Ratio of plant HTO to atmospheric HTO

Consumption rate of milk

Fodder ingestion rate (milk cattle)

Feed-to-milk transfer factor

Fraction of fodder from pasture (milk cattle)

Milk transport time (milking to consumption)

Consumption rate of beef

Fodder ingestion rate (beef cattle)

Feed-to-beef transfer factor

Fraction of fodder from pasture (beef cattle)

Beef transport time (slaughter to consumption)

Consumption rate of produce

Fraction of produce from home garden

Consumption rate of leafy vegetables

Fraction of leafy vegetables from home garden

Annual average breathing rate of adult male
$\mathrm{C}^{\mathrm{a}}$

$\mathrm{T}_{\mathrm{e}}$

$\mathrm{M}$

$\mathrm{H}$

$f_{w}$

$\mathrm{R}_{\mathrm{pa}}$

$\mathrm{U}_{\mathrm{m}}$

$I_{m}$

$f_{m}$

$f_{p m}$

$t_{m}$

$\mathrm{U}_{\mathrm{b}}$

$I_{b}$

$f_{b}$

$f_{p b}$

$t_{b}$

$U_{v}$

$f_{v}$

$\mathrm{U}_{\mathrm{I}}$

$f_{1}$

BR all

all

all

P, L, B, M

P, L, B, M

P, L, B, M

$\mathrm{M}$

M

M

M

M

B

B

B

B

B

P

$P$

L

L

I

\footnotetext{
*Pathway abbreviations: $\mathrm{P}$ - produce consumption; $\mathrm{L}$ - leafy vegetable consumption; $\mathrm{B}$ - beef consumption; M - milk consumption; I - inhalation.
} 
Table 2. Parameter distribution types, ranges, and base-case values for the atmospheric tritium dose model.

\begin{tabular}{|c|c|c|c|c|}
\hline Parameter & $\begin{array}{c}\text { Distribution } \\
\text { Type }\end{array}$ & Range $^{*}$ & $\begin{array}{c}\text { Base-Case } \\
\text { Value }^{\dagger}\end{array}$ & Units \\
\hline $\mathrm{C}^{\mathrm{a}}$ & $\mathbf{N}$ & $3.9-36.9$ & 20.4 & $\mathrm{pCi} \mathrm{m} \mathrm{m}^{-3}$ \\
\hline $\mathrm{T}_{\mathrm{e}}$ & $\mathrm{LN}$ & $334000-1690000$ & 864000 & $\mathbf{s}$ \\
\hline $\mathbf{M}$ & $\mathrm{LN}$ & $46000-107000$ & 66400 & g \\
\hline $\mathbf{H}$ & $\mathrm{N}$ & $9.7-12.8$ & 11.25 & $\mathrm{~g} \mathrm{~m}^{-3}$ \\
\hline$f_{w}$ & $\mathrm{~T}$ & $0.77-0.95$ & 0.86 & \\
\hline $\mathrm{R}_{\mathrm{pa}}$ & $\mathbf{N}$ & $0.24-0.84$ & 0.54 & \\
\hline $\mathrm{U}_{\mathrm{m}}$ & $\mathrm{LN}$ & $7.9-750$ & 230 & $\mathrm{~kg} \mathrm{yr}^{-1}$ \\
\hline $\mathrm{I}_{\mathrm{m}}$ & $\mathrm{N}$ & $4600-22000$ & 13140 & $\mathrm{~kg} \mathrm{yr}^{-1}$ \\
\hline $\mathrm{f}_{\mathrm{m}}$ & $\mathrm{U}$ & $0-0.02$ & 0.01 & $\mathrm{~d} \mathrm{~L}^{-1}$ \\
\hline $\mathrm{f}_{\mathrm{pm}}$ & $\mathrm{T}$ & $0-1$ & 0.56 & \\
\hline$t_{m}$ & $\mathrm{LN}$ & $1-10$ & 3 & $\mathrm{~d}$ \\
\hline $\mathrm{U}_{\mathrm{b}}$ & $\mathrm{LN}$ & $10-600$ & 81 & $\mathrm{~kg} \mathrm{yr}^{-1}$ \\
\hline $\mathrm{I}_{\mathrm{b}}$ & $\mathrm{N}$ & $6900-31000$ & 18980 & $\mathrm{~kg} \mathrm{yr}^{-1}$ \\
\hline$f_{b}$ & $\mathrm{U}$ & $0-0.02$ & 0.012 & $\mathrm{~d} \mathrm{~kg}^{-1}$ \\
\hline $\mathrm{f}_{\mathrm{pb}}$ & $\mathrm{T}$ & $0-1$ & 0.75 & \\
\hline$t_{b}$ & $\mathrm{LN}$ & $2-20$ & 6 & $\mathrm{~d}$ \\
\hline$U_{v}$ & $\mathrm{LN}$ & $19-1200$ & 276 & $\mathrm{~kg} \mathrm{yr}^{-1}$ \\
\hline$f_{v}$ & $\mathrm{~T}$ & $0.5-1.0$ & 0.76 & \\
\hline $\mathrm{U}_{1}$ & $\mathrm{LN}$ & $7.5-300$ & 43 & $\mathrm{~kg} \mathrm{yr}^{-1}$ \\
\hline $\mathrm{f}_{l}$ & $\mathrm{~T}$ & $0.5-1.0$ & 1.0 & \\
\hline $\mathrm{BR}$ & $\mathrm{N}$ & $3400-13600$ & 8000 & $\mathrm{~m}^{3} \mathrm{yr}^{-1}$ \\
\hline
\end{tabular}

*ange end-points are approximately \pm 3 s for normal and lognormal distributions.

tbase-case value is not necessarily the mean value of the distribution frequency. 
Table 3. Values of the normalized partial derivatives for the atmospheric tritium dose model.

$$
\begin{array}{lll}
\frac{\partial \mathrm{D}}{\partial \mathrm{C}^{\mathrm{a}}}\left(\frac{\mathrm{C}^{\mathrm{a}}}{\mathrm{D}}\right)=0.999 & \frac{\partial \mathrm{D}}{\partial \mathrm{T}_{\mathrm{e}}}\left(\frac{\mathrm{T}_{\mathrm{e}}}{\mathrm{D}}\right)=0.999 & \frac{\partial \mathrm{D}}{\partial \mathrm{M}}\left(\frac{\mathrm{M}}{\mathrm{D}}\right)=-0.999 \\
\frac{\partial \mathrm{D}}{\partial \mathrm{H}}\left(\frac{\mathrm{H}}{\mathrm{D}}\right)=-0.537 & \frac{\partial \mathrm{D}}{\partial \mathrm{f}_{\mathrm{w}}}\left(\frac{\mathrm{f}_{\mathrm{w}}}{\mathrm{D}}\right)=0.537 & \frac{\partial \mathrm{D}}{\partial \mathrm{R}_{\mathrm{pa}}}\left(\frac{\mathrm{R}_{\mathrm{pa}}}{\mathrm{D}}\right)=0.537 \\
\frac{\partial \mathrm{D}}{\partial \mathrm{U}_{\mathrm{m}}}\left(\frac{\mathrm{U}_{\mathrm{m}}}{\mathrm{D}}\right)=0.074 & \frac{\partial \mathrm{D}}{\partial \mathrm{I}_{\mathrm{m}}}\left(\frac{\mathrm{I}_{\mathrm{m}}}{\mathrm{D}}\right)=0.074 & \frac{\partial \mathrm{D}}{\partial \mathrm{f}_{\mathrm{m}}}\left(\frac{\mathrm{f}_{\mathrm{m}}}{\mathrm{D}}\right)=0.074 \\
\frac{\partial \mathrm{D}}{\partial \mathrm{f}_{\mathrm{pm}}}\left(\frac{\mathrm{f}_{\mathrm{pm}}}{\mathrm{D}}\right)=0.074 & \frac{\partial \mathrm{D}}{\partial \mathrm{t}_{\mathrm{m}}}\left(\frac{\mathrm{t}_{\mathrm{m}}}{\mathrm{D}}\right)=-3.5 \times 10^{-5} & \frac{\partial \mathrm{D}}{\partial \mathrm{U}_{\mathrm{b}}}\left(\frac{\mathrm{U}_{\mathrm{b}}}{\mathrm{D}}\right)=0.060 \\
\frac{\partial \mathrm{D}}{\partial \mathrm{I}_{\mathrm{b}}}\left(\frac{\mathrm{I}_{\mathrm{b}}}{\mathrm{D}}\right)=0.060 & \frac{\partial \mathrm{D}}{\partial \mathrm{f}_{\mathrm{b}}}\left(\frac{\mathrm{f}_{\mathrm{b}}}{\mathrm{D}}\right)=0.060 & \frac{\partial \mathrm{D}}{\partial \mathrm{f}_{\mathrm{pb}}}\left(\frac{\mathrm{f}_{\mathrm{pb}}}{\mathrm{D}}\right)=0.060 \\
\frac{\partial \mathrm{D}}{\partial \mathrm{t}_{\mathrm{b}}}\left(\frac{\mathrm{t}_{\mathrm{b}}}{\mathrm{D}}\right)=-3.7 \times 10^{-5} & \frac{\partial \mathrm{D}}{\partial \mathrm{U}_{\mathrm{v}}}\left(\frac{\mathrm{U}_{\mathrm{v}}}{\mathrm{D}}\right)=0.334 & \frac{\partial \mathrm{D}}{\partial \mathrm{f}_{\mathrm{v}}}\left(\frac{\mathrm{f}_{\mathrm{v}}}{\mathrm{D}}\right)=0.333 \\
\frac{\partial \mathrm{D}}{\partial \mathrm{U}_{\mathrm{l}}}\left(\frac{\mathrm{U}_{\mathrm{l}}}{\mathrm{D}}\right)=0.068 & \frac{\partial \mathrm{D}}{\partial \mathrm{f}_{\mathrm{l}}}\left(\frac{\mathrm{f}_{\mathrm{l}}}{\mathrm{D}}\right)=0.069 & \frac{\partial \mathrm{D}}{\partial \mathrm{BR}}\left(\frac{\mathrm{BR}}{\mathrm{D}}\right)=0.464
\end{array}
$$


Table 4. The correlation and partial correlation coefficients for the parameters in the atmospheric tritium dose model.*

Parameter $\quad r$

$\begin{array}{crr}\mathrm{C}^{\mathrm{a}} & 0.513 & 0.684 \\ \mathrm{~T}_{\mathrm{e}} & 0.502 & 0.676 \\ \mathrm{U}_{\mathrm{v}} & 0.351 & 0.540 \\ \mathrm{M} & -0.249 & -0.414 \\ \mathrm{BR} \mathrm{R}_{\mathrm{pa}} & 0.207 & 0.344 \\ \mathrm{U}_{\mathrm{l}} \mathrm{U}_{\mathrm{b}} & 0.122 & 0.203 \\ \mathrm{f}_{\mathrm{m}} & 0.105 & 0.175 \\ \mathrm{I}_{\mathrm{b}} \mathrm{f}_{\mathrm{l}} & 0.084 & 0.140 \\ \mathrm{f}_{\mathrm{v}} \mathrm{f}_{\mathrm{b}} \mathrm{U}_{\mathrm{m}} & 0.077 & 0.128 \\ \mathrm{H} & -0.063 & -0.105 \\ \mathrm{f}_{\mathrm{w}} & 0.045 & 0.075 \\ \mathrm{t}_{\mathrm{m}} \mathrm{t}_{\mathrm{b}} & -0.045 & -0.075 \\ \mathrm{f}_{\mathrm{pb}} \mathrm{I}_{\mathrm{m}} \mathrm{f}_{\mathrm{pm}} & 0.032 & 0.053\end{array}$

* the partials calculated above are third order meaning that the three highest correlations are accounted for in determining the partial. 
Table 5. Sensitivity measures by parameter and method.

\begin{tabular}{|c|c|c|c|c|c|c|c|c|c|c|}
\hline arameter & PD & $\pm 20 \%$ & $\pm \mathrm{SD}$ & SI & 11 & $\mathrm{RD}$ & RDR & PRCC & SRC & RAC \\
\hline Absolute Humidity & $<0.537>$ & 1.246 & 1.041 & 0.142 & 0.008 & 0.023 & 0.487 & $<0.105>$ & $<0.015>$ & $<0.044>$ \\
\hline Atmospheric Concentration & 0.999 & 1.500 & 1.738 & 0.894 & 0.343 & 0.269 & 0.994 & 0.684 & 0.115 & 0.537 \\
\hline Beef Cow ingestion rate & 0.060 & 1.024 & 1.031 & 0.074 & 0.193 & 0.011 & 0.052 & 0.140 & 0.059 & 0.044 \\
\hline Beef Transport Time & $<0.000>$ & 1.000 & 1.000 & .000 & 0.498 & 0.000 & 0.000 & $<0.075>$ & $<0.032>$ & 0.008 \\
\hline Biological Half-Life & 0.999 & 1.500 & 1.716 & 0.802 & 0.277 & 0.276 & 1.018 & 0.676 & 0.221 & 0.510 \\
\hline Breathing Rate & 0.464 & 1.204 & 1.268 & 0.446 & 0.168 & 0.107 & 0.534 & 0.344 & 0.146 & 0.190 \\
\hline Feed-to-Meat transfer factor & 0.060 & 1.024 & 1.132 & 0.097 & 1.307 & 0.020 & 0.042 & 0.128 & $<0.006>$ & 0.081 \\
\hline Feed-to-Milk transfer factor & 0.074 & 1.030 & 1.063 & 0. & 1.310 & 0.041 & 0.087 & 0.175 & & 0.035 \\
\hline Frac. of leafy veg. from garden & 0.069 & 1.028 & 1.049 & 0.034 & 0.073 & 06 & 0.044 & 0.140 & 0.033 & 0.055 \\
\hline Frac. of produce from garden & 0.333 & 1.143 & 1.161 & 0.199 & 0.073 & 0.040 & 0.293 & 0.128 & 0.084 & 0.074 \\
\hline Fraction from pasture (beef) & 0.060 & 1.024 & 1.105 & 0.079 & 0.986 & 0.013 & 0.036 & 0.053 & $<0.018>$ & 0.039 \\
\hline Fraction from pastu & 0.074 & 1.030 & 1.057 & 0.125 & 1.006 & 0.030 & 0.076 & 0.053 & 0. & 0.036 \\
\hline Leafy Veg. Consumption Rate & 0.068 & 1.028 & 1.126 & 0.325 & 1.394 & 53 & 0.081 & 0.203 & 0.017 & 0.116 \\
\hline Mass of Soft Tissue & $<0.999>$ & 1.500 & 1.323 & 0.568 & 0.075 & 0.140 & 0.995 & $<0.414>$ & $<0.093>$ & $<0.261\rangle$ \\
\hline Meat Consumption Rate & 0.060 & 1.024 & 1.111 & 0.320 & 1.735 & 0.042 & 0.053 & 0.203 & 0.124 & 0.105 \\
\hline Milk Consumption Rate & 0.074 & 1.030 & 1.052 & 0.204 & & 0.036 & 0.041 & 0.128 & 0.059 & 0.063 \\
\hline Milk Cow ingestion rate & 0.074 & 1.030 & 1.013 & 0.092 & 0.202 & 0.014 & 0.065 & $<0.053>$ & $<0.028>$ & 0.020 \\
\hline Milk Transport Time & $<0.000>$ & 1.000 & 1.000 & 0.000 & 0.577 & 0.000 & 0.000 & $<0.075>$ & $<0.026><$ & $<0.003\rangle$ \\
\hline Percent Water in Vegetation & 0.537 & 1.241 & & & 0.006 & 0.021 & 0.515 & 0.075 & 0.002 & 0.029 \\
\hline & 0.537 & 1.241 & 1.170 & 0.436 & & 0.138 & 0.740 & 0.344 & 0.114 & 0.219 \\
\hline Produce Consumption Rate & 0.334 & 1.143 & 1.380 & 0.673 & 1.823 & 0.169 & 0.215 & 0.540 & 0.261 & 0.380 \\
\hline
\end{tabular}

values in brackets are negative. 
Table 6. Sensitivity Measures by parameter and partitioned distribution method.

\begin{tabular}{|c|c|c|c|c|c|c|c|c|}
\hline \multirow[b]{2}{*}{ Parameter } & \multicolumn{2}{|c|}{ Smirnov } & \multirow{2}{*}{$\begin{array}{l}\text { Cramer-vo } \\
\text { Median }\end{array}$} & \multirow{2}{*}{$\begin{array}{c}\text { Mises } \\
90 \text { th } \%\end{array}$} & \multicolumn{2}{|c|}{ Mann-Whitney* } & \multicolumn{2}{|c|}{ Squared Ranks* } \\
\hline & Median & 90th\% & & & Median & 90 th\% & Median & 90th\% \\
\hline Absolute Humidity & 0.094 & 0.059 & 0.746 & 0.069 & $<240599>$ & $<448366>$ & 153 & 300.3 \\
\hline Atmospheric Concentration & 0.364 & 0.450 & 18.911 & 8.494 & 186671 & 425381 & $<164\rangle$ & $<295.5>$ \\
\hline Beef Cow ingestion rate & 0.104 & 0.099 & 0.844 & 0.234 & 236946 & 446648 & 167 & $<294.9>$ \\
\hline Beef Transport Time & 0.078 & 0.078 & 0.325 & 0.078 & $<243335>$ & $<449310>$ & 165 & 299.2 \\
\hline Biological Half-Life & 0.386 & 0.379 & 17.336 & 6.305 & 189875 & 428540 & 148 & 295.4 \\
\hline Breathing Rate & 0.156 & 0.204 & 2.370 & 1.613 & 227990 & 439266 & $<164>$ & 300.2 \\
\hline Feed-to-Meat transfer factor & 0.060 & 0.080 & 0.221 & 0.146 & 243767 & 447460 & 165 & $<299.1>$ \\
\hline Feed-to-Milk transfer factor & 0.086 & 0.104 & 0.669 & 0.423 & 238357 & 444693 & 163 & $<300.3>$ \\
\hline Frac. of leafy veg. from garden & 0.068 & 0.046 & 0.370 & 0.025 & 242019 & $<449960>$ & 162 & $<300.1>$ \\
\hline Frac. of produce from garden & 0.058 & 0.210 & 0.205 & 1.698 & 243795 & 438976 & 165 & 297.5 \\
\hline Fraction from pasture (beef) & 0.044 & 0.136 & 0.061 & 0.512 & 249155 & 444533 & $<163\rangle$ & $<297.2>$ \\
\hline Fraction from pasture (milk) & 0.046 & 0.076 & 0.089 & 0.068 & 249182 & $<449456>$ & $<163>$ & 298.1 \\
\hline Leafy Veg. Consumption Rate & 0.110 & 0.080 & 1.056 & 0.142 & 235605 & 448737 & 156 & 296.5 \\
\hline Mass of Soft Tissue & 0.196 & 0.196 & 4.257 & 1.262 & $<220324>$ & $<441152>$ & $<160\rangle$ & $<300.3>$ \\
\hline Meat Consumption Rate & 0.112 & 0.152 & 1.017 & 0.379 & 236456 & 445948 & 148 & 298.1 \\
\hline Milk Consumption Rate & 0.072 & 0.174 & 0.365 & 0.767 & 241759 & 443416 & 156 & 291.7 \\
\hline Milk Cow ingestion rate & 0.066 & 0.066 & 0.318 & 0.063 & $<243007>$ & 450446 & $<164>$ & $<299.4>$ \\
\hline Milk Transport Time & 0.062 & 0.114 & 0.264 & 0.326 & $<244307>$ & 446181 & 163 & 300.4 \\
\hline Percent Water in Vegetation & 0.058 & 0.129 & 0.138 & 0.361 & 245472 & 445501 & 166 & 298.5 \\
\hline Plant/Atm HTO Ratio & 0.172 & 0.208 & 3.373 & 1.557 & 223509 & 439951 & $<164>$ & $<293.1\rangle$ \\
\hline Produce Consumption Rate & 0.256 & 0.489 & 8.300 & 8.608 & 207762 & 425335 & 109 & 273.3 \\
\hline
\end{tabular}

"values in brackets have been normalized (see text). 
Table 7. Ranks of the sensitivity measures by parameter and method.

\begin{tabular}{|c|c|c|c|c|c|c|c|c|c|c|}
\hline Parameter & PD & $\pm 20 \%$ & $\pm S D$ & SI & 11 & $\mathbf{R D}$ & RDR & PRCC & SPC & RPC \\
\hline Absolute Humidity & & & & & & & & 15 & 19 & 13.5 \\
\hline $\begin{array}{l}\text { Absolute Humidity } \\
\text { Atmospheric Concentration }\end{array}$ & $\begin{array}{l}5 \\
2\end{array}$ & $\begin{array}{l}4 \\
2\end{array}$ & $\begin{array}{c}17 \\
1\end{array}$ & $\begin{array}{c}11 \\
1\end{array}$ & $\begin{array}{l}20 \\
11\end{array}$ & $\begin{array}{c}13 \\
2\end{array}$ & 2.5 & $\begin{array}{c}15 \\
1\end{array}$ & 5 & 1 \\
\hline Beef Cow ingestion rate & 17.5 & 17.5 & 18 & 18 & 15 & 18 & 14.5 & 10.5 & 9.5 & 13.5 \\
\hline Beef Transport Time & 20.5 & 20.5 & 20.5 & 20.5 & 10 & 20.5 & 20.5 & 17 & 12 & 20 \\
\hline Biological Half-Life & 2 & 2 & 2 & 2 & 12 & 1 & 1 & 2 & 2 & 2 \\
\hline Breathing Rate & 7 & 7 & 5 & 5 & 16 & 6 & 5 & 5.5 & 3 & 6 \\
\hline Feed-to-Meat transfer factor & 17.5 & 17.5 & 8 & 15 & 6 & 15 & 17 & 13 & 20 & 9 \\
\hline Feed-to-Milk transfer factor & 11.5 & 11.5 & 13 & 12 & 5 & 9 & 10 & 9 & 15 & 17 \\
\hline Frac. from pasture (beef) & 17.5 & 17.5 & 11 & 17 & 8 & 17 & 19 & 20 & 16.5 & 15 \\
\hline Frac, from pasture (milk) & 11.5 & 11.5 & 14 & 13 & 7 & 12 & 12 & 20 & 16.5 & 16 \\
\hline Frac. of leafy veg. from garden & 14.5 & 14.5 & 16 & 19 & 19 & 19 & 16 & 10.5 & 11 & 12 \\
\hline Frac. of produce from garden & 8.5 & 8.5 & 7 & 10 & 18 & 10 & 8 & 13 & 8 & 10 \\
\hline Leafy Veg. Consumption Rate & 14.5 & 14.5 & 9 & 7 & 4 & 7 & 11 & 7.5 & 18 & 7 \\
\hline Mass of Soft Tissue & 2 & 2 & 4 & 4 & 17 & 4 & 2.5 & 4 & 7 & 4 \\
\hline Meat Consumption Rate & 17.5 & 17.5 & 10 & 8 & 3 & 8 & 14.5 & 7.5 & 4 & 8 \\
\hline Milk Consumption Rate & 11.5 & 11.5 & 15 & 9 & 1 & 11 & 18 & 13 & 9.5 & 11 \\
\hline Milk Cow ingestion rate & 11.5 & 11.5 & 19 & 16 & 14 & 16 & 13 & 20 & 13 & 19 \\
\hline Milk Transport Time & 20.5 & 20.5 & 20.5 & 20.5 & 9 & 20.5 & 20.5 & 17 & 14 & 21 \\
\hline Percent Water in Vegetation & 5 & 5.5 & 12 & 14 & 21 & 14 & 6 & 17 & 21 & 18 \\
\hline Plant/Atm HTO Ratio & 5 & 5.5 & 6 & 6 & 13 & 5 & 4 & 5.5 & 6 & 5 \\
\hline Produce Consumption Rate & 8.5 & 8.5 & 3 & 3 & 2 & 3 & 9 & 3 & 1 & 3 \\
\hline
\end{tabular}


Table 8. Sensitivity ranks by parameter and partitioned distribution method.

\begin{tabular}{|c|c|c|c|c|c|c|c|c|}
\hline \multirow[b]{2}{*}{ Parameter } & \multicolumn{2}{|c|}{ Smirnov } & \multirow{2}{*}{$\begin{array}{l}\text { Cramer-vo } \\
\text { Median }\end{array}$} & \multirow{2}{*}{$\begin{array}{l}\text { Mises } \\
\text { 90th }\end{array}$} & \multicolumn{2}{|c|}{ Mann-Whitney } & \multicolumn{2}{|c|}{ Squared Ranks } \\
\hline & Median & 90 th & & & Median & 90 th & Median & 90th \\
\hline Absolute Humidity & 10 & 20 & 10 & 18 & 11 & 16 & 4 & 19 \\
\hline Atmospheric Concentration & 2 & 2 & 1 & 2 & 1 & 2 & 14.5 & 5.5 \\
\hline Beef Cow ingestion rate & 9 & 14 & 9 & 14 & 9 & 14 & 21 & 4 \\
\hline Beef Transport Time & 12 & 17 & 14 & 17 & 15 & 18 & 18 & 13.5 \\
\hline Biological Half-Life & 1 & 3 & 2 & 3 & 2 & 3 & 2.5 & 5.5 \\
\hline Breathing Rate & 6 & 6 & 6 & 5 & 6 & 5 & 14.5 & 17 \\
\hline Feed-to-Meat transfer factor & 17 & 15.5 & 17 & 15 & 16 & 15 & 18 & 13.5 \\
\hline Feed-to-Milk transfer factor & 11 & 13 & 11 & 10 & 10 & 10 & 10.5 & 19 \\
\hline Frac. from pasture (beef) & 21 & 10 & 21 & 9 & 20 & 9 & 10.5 & 8 \\
\hline Frac. from pasture (milk) & 20 & 18 & 20 & 19 & 21 & 19 & 10.5 & 10.5 \\
\hline Frac. of leafy veg. from garden & 14 & 21 & 12 & 21 & 13 & 20 & 8 & 16 \\
\hline Frac. of produce from garden & 18.5 & 4 & 18 & 4 & 17 & 4 & 18 & 9 \\
\hline Leafy Veg. Consumption Rate & 8 & 15.5 & 7 & 16 & 7 & 17 & 5.5 & 7 \\
\hline Mass of Soft Tissue & 4 & 7 & 4 & 7 & 4 & 7 & 7 & 19 \\
\hline Meat Consumption Rate & 7 & 9 & 8 & 11 & 8 & 12 & 2.5 & 10.5 \\
\hline Milk Consumption Rate & 13 & 8 & 13 & 8 & 12 & 8 & 5.5 & 2 \\
\hline Milk Cow ingestion rate & 15 & 19 & 15 & 20 & 14 & 21 & 14.5 & 15 \\
\hline Milk Transport Time & 16 & 12 & 16 & 13 & 18 & 13 & 10.5 & 20 \\
\hline Percent Water in Vegetation & 18.5 & 11 & 19 & 12 & 19 & 11 & 20 & 12 \\
\hline Plant/Atm HTO Ratio & 5 & 5 & 5 & 6 & 5 & 6 & 14.5 & 3 \\
\hline Produce Consumption Rate & 3 & 1 & 3 & 1 & 3 & 1 & 1 & 1 \\
\hline
\end{tabular}


Table 9. Comparison of the "true" ranking order and the sensitivity index ranking.

\begin{tabular}{|c|c|c|c|}
\hline Parameter & $\begin{array}{l}\text { "True" } \\
\text { Ranking }\end{array}$ & $\begin{array}{l}\text { Sensitivity Index } \\
\text { Ranking }\end{array}$ & $\begin{array}{c}\text { Squared } \\
\text { Difference }\end{array}$ \\
\hline $\mathrm{T}_{\mathrm{e}}$ & 1 & 2 & 1 \\
\hline $\mathrm{C}^{\mathrm{a}}$ & 2 & 1 & 1 \\
\hline $\mathrm{U}_{\mathrm{v}}$ & 3 & 3 & 0 \\
\hline $\mathbf{M}$ & 4 & 4 & 0 \\
\hline $\mathrm{R}_{\mathrm{pa}}$ & 5 & 6 & 1 \\
\hline $\mathrm{BR}$ & 6 & 5 & 1 \\
\hline $\mathrm{U}_{\mathrm{b}}$ & 7 & 8 & 1 \\
\hline $\mathrm{U}_{\mathrm{l}}$ & 8 & 7 & 1 \\
\hline$f_{v}$ & 9 & 10 & 1 \\
\hline $\mathrm{U}_{\mathrm{m}}$ & 10 & 9 & 1 \\
\hline $\mathrm{f}_{\mathrm{m}}$ & 11 & 12 & 1 \\
\hline $\mathrm{H}$ & 12 & 11 & 1 \\
\hline $\mathrm{f}_{\mathrm{pm}}$ & 13.5 & 13 & 0.25 \\
\hline $\mathrm{f}_{\mathrm{w}}$ & 13.5 & 14 & 0.25 \\
\hline$f_{b}$ & 15 & 15 & 0 \\
\hline$f_{1}$ & 16 & 19 & 9 \\
\hline $\mathrm{I}_{\mathrm{b}}$ & 17 & 18 & 1 \\
\hline $\mathrm{I}_{\mathrm{m}}$ & 18 & 16 & 4 \\
\hline $\mathrm{f}_{\mathrm{pb}}$ & 19 & 17 & 4 \\
\hline$t_{b}$ & 20 & 20.5 & 0.25 \\
\hline \multirow[t]{2}{*}{$t_{m}$} & 21 & 20.5 & 0.25 \\
\hline & & Performance Index: & 29 \\
\hline
\end{tabular}


Table 10. Sensitivity ranking based on overall rank. Ten most sensitive parameters shown for each method.

\begin{tabular}{|c|c|c|c|c|c|c|c|c|c|c|c|}
\hline $\begin{array}{l}\text { "True" } \\
\text { Rank }\end{array}$ & Parameter & $\mathrm{SI}$ & $\mathrm{RD}$ & RAC & $\pm \mathrm{SD}$ & PROC & RDR & $\mathrm{PD}$ & $\pm 20 \%$ & SRC & 11 \\
\hline 1 & Biological Half-Life & 2 & 1 & 2 & 2 & 2 & 1 & 2 & 2 & 2 & \\
\hline 2 & Atmospheric Concentration & 1 & 2 & 1 & 1 & 1 & 2.5 & 2 & 2 & 5 & \\
\hline 3 & Produce Consumption Rate & 3 & 3 & 3 & 3 & 3 & 9 & 8.5 & 8.5 & 1 & 2 \\
\hline 4 & Mass of Soft Tissue & 4 & 4 & 4 & 4 & 4 & 2.5 & 2 & 2 & 7 & \\
\hline 5 & Plant/Atm HTO Ratio & 6 & 5 & 5 & 6 & 5.5 & 4 & 5 & 5.5 & 6 & \\
\hline 6 & Breathing Rate & 5 & 6 & 6 & 5 & 5.5 & 5 & 7 & 7 & 3 & \\
\hline 7 & Meat Consumption Rate & 8 & 8 & 8 & 10 & 7.5 & & & & 4 & 3 \\
\hline 8 & Leafy Veg. Consumption Rate & 7 & 7 & 7 & 9 & 7.5 & & & & & 4 \\
\hline 9 & Frac. of produce from garden & 10 & 10 & 10 & 7 & & 8 & 8.5 & 8.5 & 8 & \\
\hline 10 & Milk Consumption Rate & 9 & & & & & & & & 9.5 & 1 \\
\hline 11 & Feed-to-Milk transfer factor & & 9 & & & 9 & 10 & & & & 5 \\
\hline 12 & Absolute Humidity & & & & & & 7 & 5 & 4 & & \\
\hline 13.5 & Frac. from pasture (milk) & & & & & & & & & & 7 \\
\hline 13.5 & Percent Water in Vegetation & & & & & & 6 & 5 & 5.5 & & \\
\hline 15 & Feed-to-Meat transfer factor & & & 9 & 8 & & & & & & 6 \\
\hline 16 & Frac. of leafy veg. from garden & & & & & & & & & & \\
\hline 17 & Beef Cow ingestion rate & & & & & & & & & & \\
\hline 18 & Milk Cow ingestion rate & & & & & & & & & 9.5 & \\
\hline 19 & Frac. from pasture (beef) & & & & & & & & & & 8 \\
\hline 20 & Beef Transport Time & & & & & & & & & & 10 \\
\hline 21 & Milk Transport Time & & & & & & & & & & 9 \\
\hline & Performance Index & 29 & 30 & 152 & 190 & 202 & 291 & 370.5 & 377.5 & 524 & 1404 \\
\hline
\end{tabular}


Table 11. Sensitivity ranking based on "true" ranking. Ten most sensitive parameters shown for each partitioned distribution method.

\begin{tabular}{|c|c|c|c|c|c|c|c|c|}
\hline \multirow[b]{2}{*}{ Parameter } & \multicolumn{2}{|c|}{ Smirnov } & \multirow{2}{*}{$\begin{array}{l}\text { Cramer-von } \\
\text { Median }\end{array}$} & \multirow{2}{*}{$\begin{array}{l}\text { Mises } \\
\text { 90th }\end{array}$} & \multicolumn{2}{|c|}{ Mann-Whitney } & \multicolumn{2}{|c|}{ Squared Ranks } \\
\hline & Median & 90th & & & Median & 90 th & Median & 90th \\
\hline Biological Half-Life & 1 & 3 & 2 & 3 & 2 & 3 & 2.5 & 5.5 \\
\hline Atmospheric Concentration & 2 & 2 & 1 & 2 & 1 & 2 & & 5.5 \\
\hline Produce Consumption Rate & 3 & 1 & 3 & 1 & 3 & 1 & 1 & 1 \\
\hline Mass of Soft Tissue & 4 & 7 & 4 & 7 & 4 & 7 & 7 & \\
\hline Plant/Atm HTO Ratio & 5 & 5 & 5 & 6 & 5 & 6 & & 3 \\
\hline Breathing Rate & 6 & 6 & 6 & 5 & 6 & 5 & & \\
\hline Frac. of produce from garden & & 4 & & 4 & & 4 & & 9 \\
\hline Meat Consumption Rate & 7 & 9 & 8 & & 8 & & 2.5 & 10.5 \\
\hline Leafy Veg. Consumption Rate & 8 & & 7 & & 7 & & 5.5 & 7 \\
\hline Milk Consumption Rate & & 8 & & 8 & & 8 & 5.5 & 2 \\
\hline Feed-to-Milk transfer factor & & & & 10 & 10 & 10 & 10.5 & \\
\hline Absolute Humidity & 10 & & 10 & & & & 4 & \\
\hline $\begin{array}{l}\text { Percent Water in Vegetation } \\
\text { Frac. from pasture (milk) }\end{array}$ & & & & 12 & & & 10.5 & 10.5 \\
\hline $\begin{array}{l}\text { Feed-to-Meat transfer factor } \\
\text { Milk Cow ingestion rate }\end{array}$ & & & & & & & & \\
\hline $\begin{array}{l}\text { Milk Cow ingestion rate } \\
\text { Frac. of leafy veg. from garden }\end{array}$ & & & & & & & 8 & \\
\hline $\begin{array}{l}\text { Frac. of leafy veg. from garden } \\
\text { Beef Cow ingestion rate }\end{array}$ & 9 & & 9 & & 9 & & & 4 \\
\hline Frac. from pasture (beef) & & 10 & & 9 & & 9 & 10.5 & 8 \\
\hline $\begin{array}{l}\text { Beef Transport Time } \\
\text { Milk Transport Time }\end{array}$ & & & & & & & 10.5 & \\
\hline
\end{tabular}


Table 12. Sums of the squared rank-differences between tests.

\begin{tabular}{|c|c|c|c|c|c|c|c|c|c|}
\hline $\begin{array}{c}\text { Sensitivity } \\
\text { Test }\end{array}$ & $\pm 20 \%$ & SI & $\pm \mathrm{SD}$ & PD & II & $\mathrm{RD}$ & RDR & PRCC & SRC \\
\hline SI & 366 & & & & & & & & \\
\hline $\pm S D$ & 552 & 198 & & & & & & & \\
\hline $\mathrm{PD}$ & 1.5 & 362 & 534 & & & & & & \\
\hline II & 2163 & 1335 & 1433 & 2156 & & & & & \\
\hline $\mathrm{RD}$ & 393 & 22 & 180 & 384 & 1291 & & & & \\
\hline RDR & 100 & 312 & 422 & 94 & 2164 & 291 & & & \\
\hline PRCC & 729 & 291 & 348 & 720 & 1399 & 263 & 542 & & \\
\hline SRC & 1002 & 594 & 699 & 996 & 1408 & 603 & 925 & 414 & \\
\hline RRC & 640 & 181 & 157 & 645 & 1387 & 217 & 540 & 176 & 515 \\
\hline
\end{tabular}


Table 13. Sums of the squared rank-differences between tests on partitioned distributions.

\begin{tabular}{cccccccc}
\hline $\begin{array}{c}\text { Sensitivity } \\
\text { Test }\end{array}$ & $S(50)$ & $S(90)$ & CM (50) & CM (90) & MW (50) & MW (90) & SR (50) \\
\hline S (90) & 731 & & & & & & \\
CM (50) & 13 & 752 & & & & & \\
CM (90) & 724 & 25 & 740 & & & & \\
MW (50) & 28 & 691 & 14 & 670 & & 1294 & \\
MW (90) & 745 & 48 & 754 & 10 & 690 & 1384 \\
SR (50) & 904 & 1311 & 904 & 1303 & 935 & 1294 \\
SR (90) & 1111 & 743 & 1114 & 827 & 1049 & 867 & \\
\hline
\end{tabular}



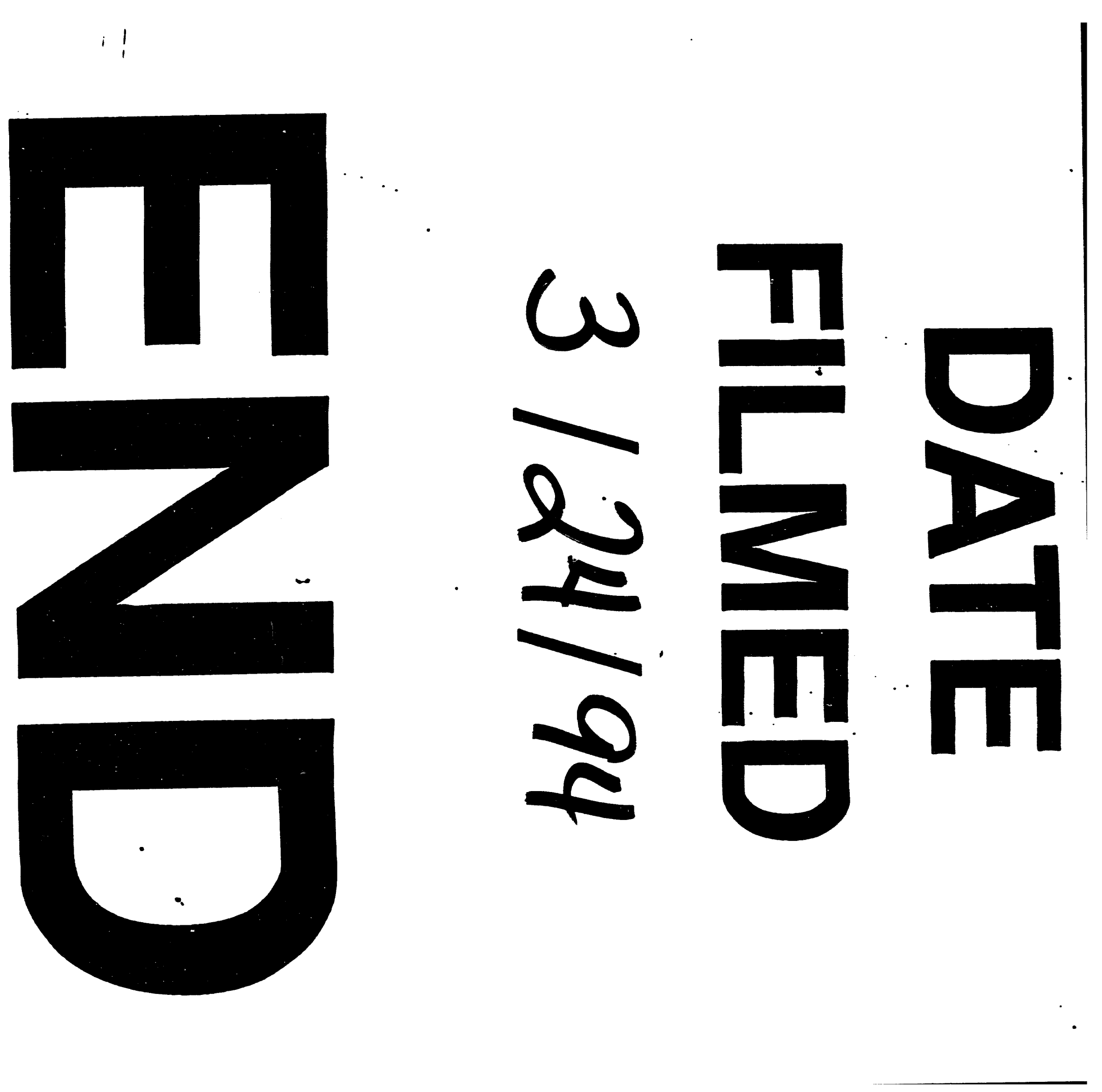


$$
-
$$

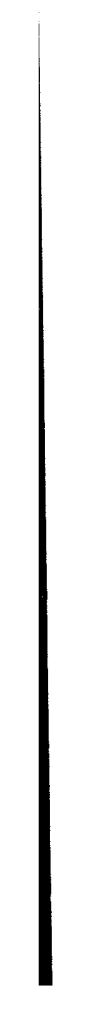

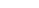

